\title{
Hospitalization Required
}

National Cancer Institute

\section{Source}

National Cancer Institute. Hospitalization Required. NCI Thesaurus. Code C50414.

A patient condition where evaluation and/or treatment in a hospital is considered

mandatory. 